\title{
An Immuno-Suppressive Aphid Saliva Protein Is Delivered into the Cytosol of Plant Mesophyll Cells During Feeding
}

\author{
Sam T. Mugford, Elaine Barclay, Claire Drurey, Kim C. Findlay, and Saskia A. Hogenhout \\ Cell and Developmental Biology, John Innes Centre, Norwich, NR4 7UH, U.K. \\ Accepted 13 October 2016.
}

\begin{abstract}
Herbivore selection of plant hosts and plant responses to insect colonization have been subjects of intense investigations. A growing body of evidence suggests that, for successful colonization to occur, (effector/virulence) proteins in insect saliva must modulate plant defense responses to the benefit of the insect. A range of insect saliva proteins that modulate plant defense responses have been identified, but there is no direct evidence that these proteins are delivered into specific plant tissues and enter plant cells. Aphids and other sap-sucking insects of the order Hemiptera use their specialized mouthparts (stylets) to probe plant mesophyll cells until they reach the phloem cells for long-term feeding. Here, we show, by immunogold-labeling of ultrathin sections of aphid feeding sites, that an immuno-suppressive aphid effector localizes in the cytoplasm of mesophyll cells near aphid stylets but not in cells further away from aphid feeding sites. In contrast, another aphid effector protein localizes in the sheaths composed of gelling saliva that surround the aphid stylets. Thus, insects deliver effectors directly into plant tissue. Moreover, different aphid effectors locate extracellularly in the sheath saliva or are introduced into the cytoplasm of plant cells.
\end{abstract}

Insect herbivores likely modulate a range of plant processes in order to successfully colonize their host plants. A growing body of evidence suggests that the saliva of herbivorous insects contains virulence factors (effectors) that interfere with host plant defenses and facilitate colonization (Atamian et al. 2013; Bos et al. 2010; Chaudhary et al. 2014; Elzinga et al. 2014; Guo et al. 2014; Musser et al. 2002; Mutti et al. 2008; Naessens et al. 2015; Pitino and Hogenhout 2013; Rodriguez et al. 2014; Stuart et al. 2012; Wang et al. 2015; Will et al. 2007). Sap-sucking insects of the order Hemiptera, such as aphids, whiteflies, leafhoppers, psyllids, and planthoppers, are stealthy feeders. These insects possess piercing-sucking mouthparts, consisting of a pair of stylets, that navigate to vascular elements for long-term feeding. Hemipterans cause direct feeding damage to plants and also transmit the majority of plant viruses and several plant-pathogenic bacteria (Guerrieri and Digilio 2008; Hogenhout et al. 2008; Orlovskis et al. 2015).

Current address for C. Drurey: Institute of Infection, Immunity and Inflammation, Glasgow University, G12 8TA, U.K.

Corresponding author: S. A. Hogenhout; E-mail: saskia.hogenhout@jic.ac.uk

*The $\boldsymbol{e}$-Xtra logo stands for "electronic extra" and indicates that three supplementary figures are published online.

(c) (i) $(9)($ Copyright $(C) 2016$ The Author(s). This is an open access article distributed under the CC BY-NC-ND 4.0 International license.
The green peach aphid (GPA) Myzus persicae alone transmits over 100 plant viruses.

The feeding behavior of aphids has been studied extensively. While navigating to the phloem, in the pathway phase, aphid stylets probe various plant cells of the mesophyll (Tjallingii 2006). During a probe, the aphid stylets penetrate cells, deposit watery saliva inside, and acquire cell contents (Martín et al. 1997). The pathway phase continues until the aphid reaches a phloem sieve-element cell, where they remain to feed, often for many hours. The phloem-feeding phase starts with release of saliva, followed by extended periods of phloem sap acquisition that are occasionally interrupted with short salivation periods (Tjallingii and Esch 1993). Whereas it has been shown that the probing of mesophyll cells is responsible for the transmission of a diversity of viruses by aphids, the biological significance of this behavior to the aphids themselves is not fully understood.

Aphids produce different types of saliva, i.e., 'gelling' saliva that forms a sheath around the stylets that is thought to have a protective function (Miles 1999) and 'watery' saliva that is thought to be injected into plant cells during the pathway and phloem-feeding phases (Martín et al. 1997; Tjallingii and Esch 1993). A number of proteins are detected in aphid saliva (Carolan et al. 2009; Chaudhary et al. 2015; Cooper et al. 2010; Harmel et al. 2008; Ramsey et al. 2007; Nicholson and Puterka 2014; Nicholson et al. 2012; Rao et al. 2013; Vandermoten et al. 2014). Aphid saliva proteins have also been detected in lysate of plant tissues previously exposed to aphids (Mutti et al. 2008; Naessens et al. 2015). Some components of aphid saliva trigger plant defense responses that are characteristic of patterntriggered immunity (PTI), including reactive oxygen species (ROS) bursts and callose deposition, which require the plant membrane-associated receptor-like kinase BRASSINOSTEROID INSENSITIVE 1-ASSOCIATED KINASE (BAK1) (Chaudhary et al. 2014; Prince et al. 2014). BAK1 is a key regulator of several cell membrane-localized pattern recognition receptors (PRRs), which mediate the first step of the plant defense response via the recognition of pathogen-associated molecular patterns, such as flg22 (Chaudhary et al. 2014; Chinchilla et al. 2007).

Aphid saliva contains effectors that suppress plant defense responses (Atamian et al. 2013; Bos et al. 2010; Chaudhary et al. 2014; Elzinga et al. 2014; Guo et al. 2014; Mutti et al. 2008; Naessens et al. 2015; Pitino and Hogenhout 2013; Rodriguez et al. 2014; Wang et al. 2015; Will et al. 2007). Mp10 is one of a number of candidate effector proteins that have been identified and was found to suppress the plant ROS burst in response to flg22 (Bos et al. 2010; Rodriguez et al. 2014). Mp10 and another candidate effector protein expressed in GPA salivary glands, MpOS-D1, belong to the chemosensory protein (CSP) family (Bos et al. 2010; Zhou et al. 2010). Other aphid effector candidates, such as MpPIntO1 and MpC002, 
promote aphid colonization (Coleman et al. 2015; Mutti et al. 2008; Pitino and Hogenhout 2013; Pitino et al. 2011) and are found in aphid saliva or in extracts of aphid-exposed leaves or both (Harmel et al. 2008; Mutti et al. 2008). However, evidence that insects deliver effectors directly into plant cells is currently lacking.

How pathogens and pests deliver effectors to the appropriate site of action has been a major research topic of many research groups (Dodds and Rathjen 2010). Gram-negative bacterial pathogens deliver their effectors via specialized mechanisms, such as type III secretion systems (Gopalan et al. 1998). For fungi and oomycetes, it was discovered that effectors require conserved sequences, such as an RXLR motif, at their $\mathrm{N}$ termini for entering the plant host, but the mechanisms underlying their delivery is not fully understood (Petre and Kamoun 2014). It is, as yet, unclear how, where, and when aphids deposit their effectors in the plant; they may do so via the 'gelling' saliva, to embed the proteins within the sheaths surrounding the stylets in the apoplastic space of plant tissue, or via 'watery' saliva, to introduce them into plant cells. In addition, aphids may secrete different effectors during the pathway and phloem-feeding phases.

Here, we studied ultrathin sections of plant tissues containing tracks of aphid stylets and used antisera raised to the aphid effectors Mp10, MpOS-D1, MpC002, and MpPIntO1 for immuno-gold labeling (IGL) of the sections. Antisera of Mp10 but not of MpOS-D1 labeled the cytosol and chloroplasts of plant mesophyll cells adjacent to aphid stylet tracks, whereas antisera to MpPIntO1 and MpC002 labeled the aphid stylet sheaths. These data indicate that aphid effectors are delivered into the cytosol of plant cells during probing in the pathway phase, whereas other effectors are embedded within the sheaths that surround the stylets in the apoplastic space of mesophyll tissue.

\section{RESULTS}

\section{Candidate effector proteins are detected} in total protein extracts of aphid-exposed leaves.

Affinity-purified antisera were raised against recombinant GPA candidate effectors and were examined for specificity and background levels in aphid and plant extracts by protein immuno-blotting. The antisera to Mp10, MpOSD1, MpPIntO1, and $\mathrm{MpC} 002$ detected bands of the predicted sizes in total protein extracted from whole aphids (Fig. 1). Antisera to the CSPs Mp10 and MpOS-D1 detected Mp10 and MpOS-D1, respectively, down to the nanogram level (Supplementary Fig. S1), indicating that the antisera to these proteins are specific and sensitive. The antisera to all four effectors detected proteins of the predicted sizes in extracts of Arabidopsis thaliana leaves previously exposed to GPA (Fig. 1) but not in unexposed leaves. These bands were not detected in blots probed with corresponding preimmune sera (Supplementary Fig. S2). The Mp10 and MpOS-D1 antibodies and preimmune sera reacted with some nonspecific bands of different sizes in the aphid-infested

\section{Plant extract $\quad$ Aphid extract}
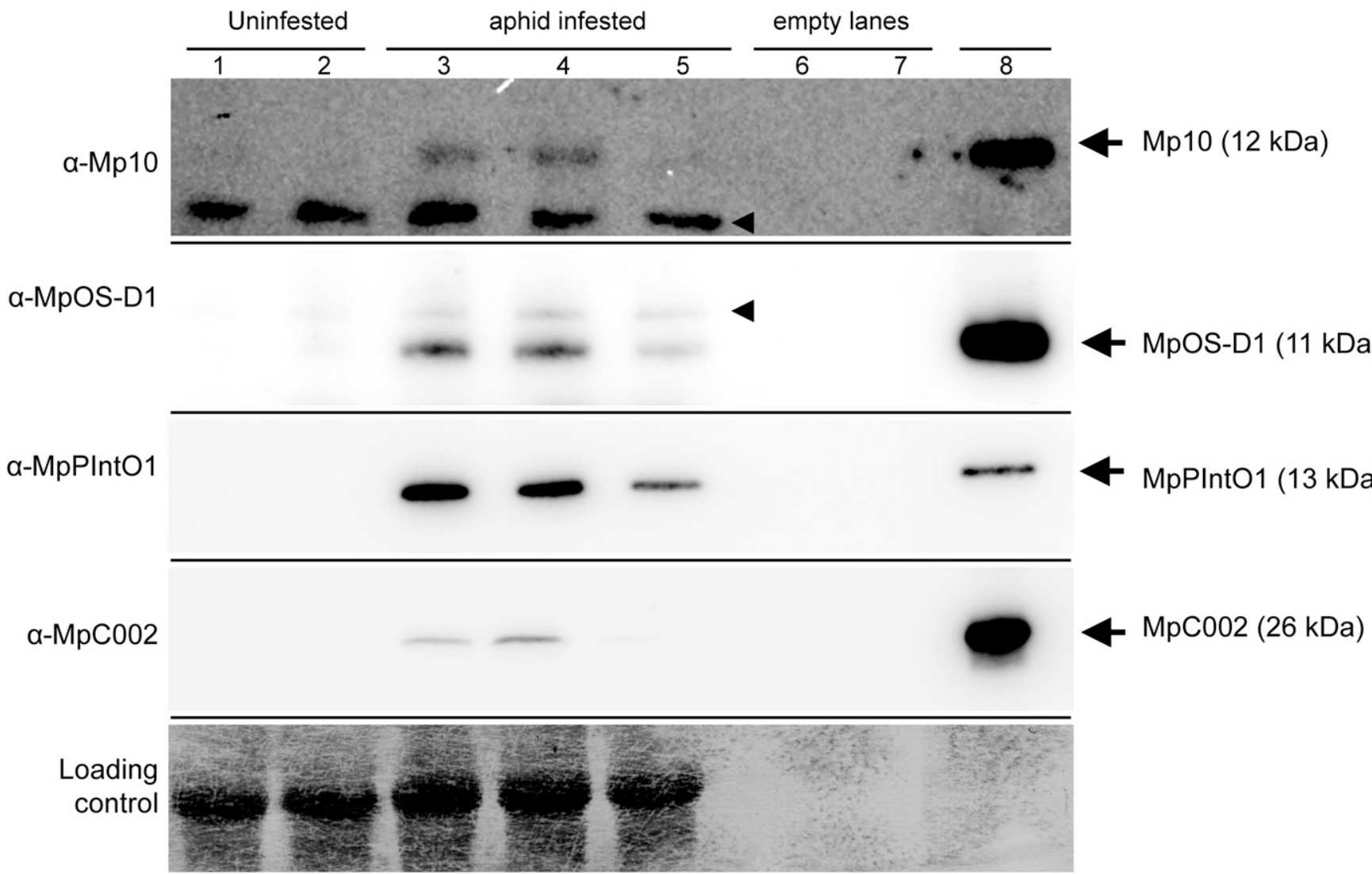

Fig. 1. Aphid salivary proteins are detected in extracts of aphid-infested host plant tissue. Total protein extracts from whole green peach aphids (GPA) (lane 8) and Arabidopsis thaliana rosettes uninfested (lanes 1 and 2, two different plants) or infested with GPA (lanes 3 to 5, three different plants) were separated by sodium dodecyl sulfate-polyacrylamide gel electrophoresis, were transferred to nitrocellulose membranes, and were probed with antisera raised against the aphid proteins Mp10, MpOS-D1, MpPIntO1, and MpC002 as shown at the left of the blots. The bottom panel shows an amido-black-stained loading control. Arrows at right point to bands of predicted sizes for the effectors, as indicated. Arrowheads indicate nonspecific bands detected by antibodies. 
and uninfested plant tissues, but the bands corresponding to the Mp10 and MpOS-D1 proteins were only detected in infested tissues and not with the preimmune sera (Fig. 1). Thus, GPA delivers all four effectors into plant tissues during feeding.

\section{The aphid effector protein Mp10 localizes} to the cytoplasm and chloroplasts of mesophyll cells adjacent to aphid feeding sites.

To investigate whether GPA delivers effectors in or near feeding sites, semithin sections of GPA-infested leaf samples were stained with toluidine blue to localize GPA stylet tracks (Fig. 2A). Ultrathin sections of the same sample were then used for IGL with the Mp10 antiserum (Fig. 2B to D). Controls included the GPA-infested $A$. thaliana leaf sample sections incubated with preimmune sera and sections of uninfested $A$. thaliana leaf samples incubated with antisera (Figs. 3 and 4).

IGL with Mp10 antiserum (dilutions 1:10 and 1:100) showed high labeling density in cytoplasm and chloroplasts of mesophyll cells adjacent to the aphid stylet tracks (Figs. 2B to D and $3 \mathrm{~A}$ and $\mathrm{B}$ ), whereas the preimmune sera (dilution 1:50) labeled uniformly across different compartments at a low level (Fig. 3C). In sections of uninfested control samples, the Mp10 antisera (1:100) did not label any compartments above background level (Fig. 3D). Thus, despite some aspecific labeling of plant proteins on immuno-blots (Fig. 1), the labeling of plant tissue adjacent to the aphid feeding site is specific. Quantification of the labeling seen on micrographs revealed consistently more labeling with Mp10 antisera of the cytosol and chloroplasts with Mp10 antisera in mesophyll cells adjacent to aphid feeding sites compared with the two control treatments (Fig. 3G; Supplementary Fig. S3). Labeling of mesophyll cells distal to the site of feeding was not detected (Fig. 3E). Results shown are representative of two independent experiments. Chloroplasts are known to be prone to high levels of nonspecific background labeling in IGL experiments; however, we do not see similar levels of labeling of plastids in the uninfested or preimmune controls or of plastids distal to the site of feeding. Therefore, these data suggest that Mp10 localizes in the cytosol and chloroplasts of mesophyll cells adjacent to the stylet tracks.

Occasionally, we found that cells adjacent to a stylet track contained unusual features (Fig. 3A and C). The cytoplasm of these cells showed reduced granularity and a higher number of vesicle-like structures that may be endoplasmic reticulumderived. These were not seen in all aphid-infested samples (Fig. 3B) but may represent a response of the cell to aphid probing.

Because GPA feeds from the phloem, we quantified Mp10 antisera labeling of the vascular bundles closest to the aphid feeding site (Figs. 2A and 3F). We did not detect specific
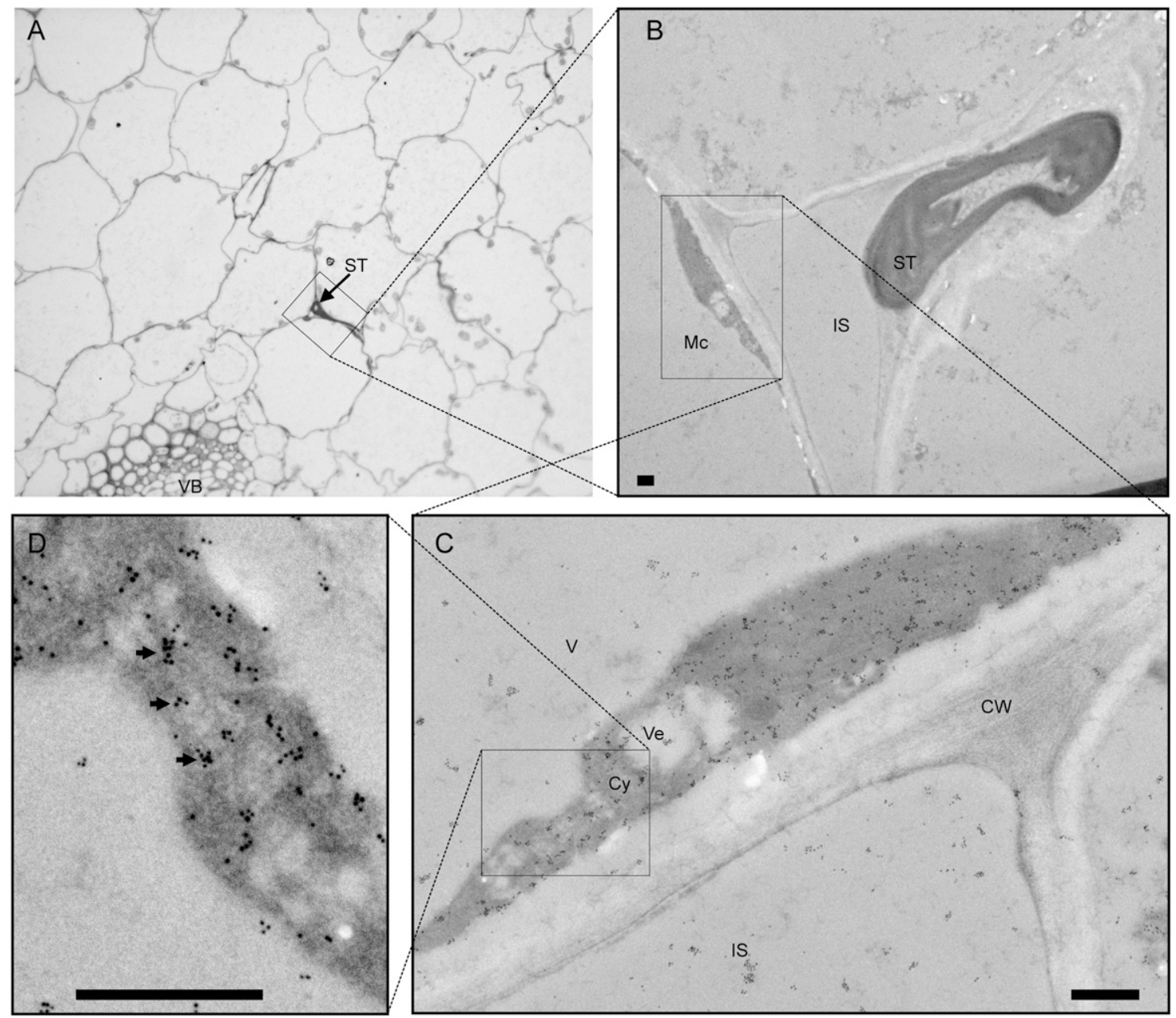

Fig. 2. Mp10 protein is detected in the cytoplasm of mesophyll cells near an aphid stylet track. A, Semithin section (0.5 $\mu \mathrm{m})$ from an aphid-infested Arabidopsis thaliana leaf stained with toluidine blue. Aphid stylet tracks (ST) are visible between mesophyll cells and a vascular bundle (VB). B to D, Immuno-gold labeling of ultrathin sections $(90 \mathrm{~nm})$ of the tissue shown in (A) with anti-Mp10 (1:10 dilution) revealed a high density of gold particles (arrows in D) in the cytoplasm (Cy) of mesophyll cells (Mc). No obvious labeling was observed of aphid stylets (St), cell wall (CW), intercellular space (IS), mesophyll cell vacuole (V), or inside vesicles (Ve). Images shown in B to D are sequentially higher magnifications of the same area of a cell adjacent to the stylet track. Scale bars, $500 \mathrm{~nm}$. 

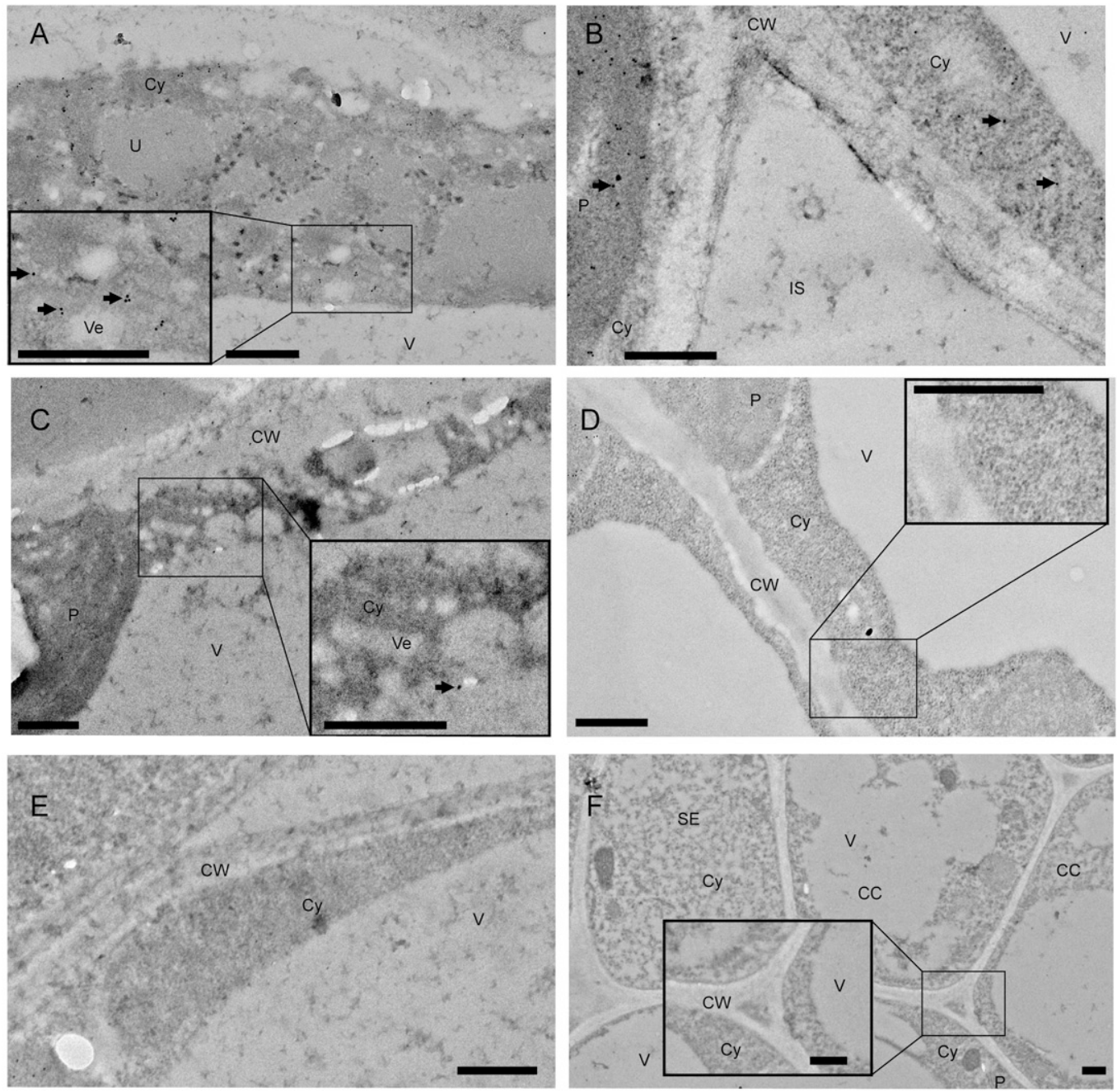

G

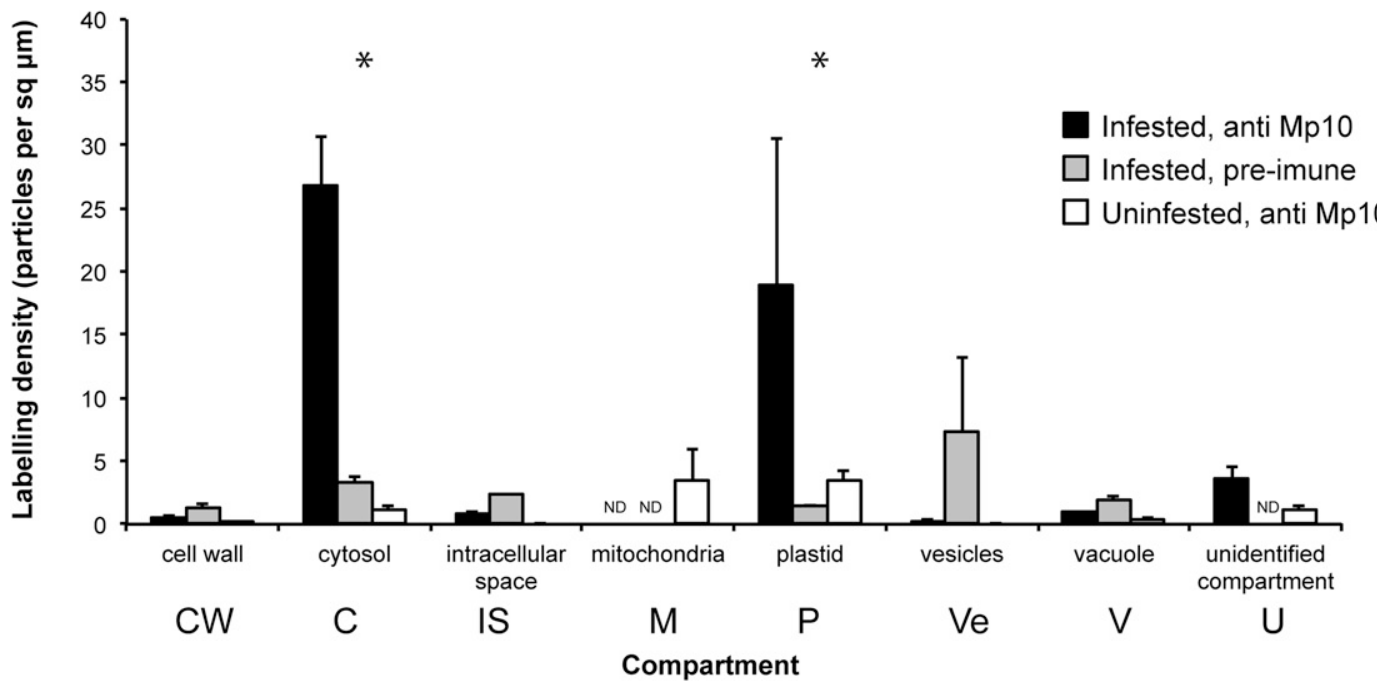

Fig. 3. Mp10 detection is specific and restricted to the cells adjacent to stylet tracks. A through $\mathbf{F}$, Ultrathin sections from Arabidopsis thaliana leaves infested with green peach aphids (GPA) and labeled with anti-Mp10 (1:100 dilution) show labeling (examples indicated with arrows) in the cytosol "Cy" (A, B, G) and plastid "P" (B, G) of cells adjacent to the stylet track but not when labeled with preimmune serum $(1: 50)(\mathrm{C}, \mathrm{G})$. Samples from uninfested plants are not labeled with anti-Mp10 above background levels (D, G). Labeling with anti-Mp10 was not detected in mesophyll cells distal to the feeding site (E) or an area of the vascular bundle closest to the feeding site in GPA-infested tissues (F). G, Quantification of labeling density based on measurements of compartment area and gold particle count across multiple images of different areas from the samples. Values show mean ( \pm standard error of the mean) density (infested, anti-Mp10 [at 1:100 dilution], $n=13$; infested, preimmune [1:50], $n=4$; uninfested anti-Mp10 [1:100], $n=5$ ). Asterisks indicate significant differences in labeling both between infested versus uninfested samples and between anti-Mp10 and preimmune labeled samples for that compartment $(P<0.01$, general linear model). IS, intercellular space; Cy, cytoplasm; V, vacuole; CW, cell wall; Ve, vesicles; P, plastid; U, unidentified compartment; CC, phloem companion cell; and SE, phloem sieve elements. Insets (A, C, D and F) are magnified regions of the image; all scale bars are $500 \mathrm{~nm}$. 

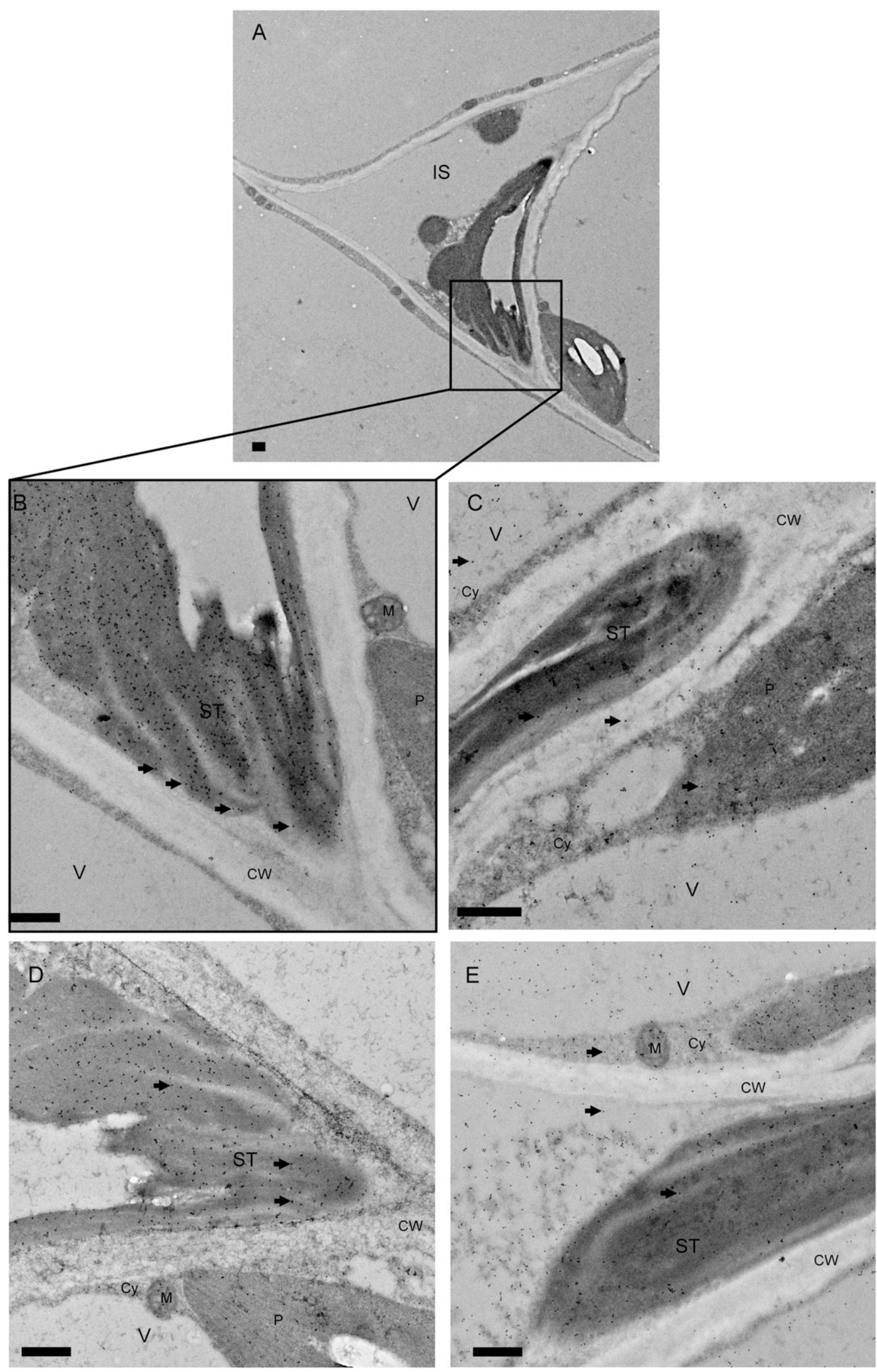

Fig. 4. MpPIntO1 and MpC002 antisera label the stylet sheaths. A to E, Ultrathin sections from aphid-infested samples showing the gelling saliva that forms the stylets sheath, immuno-gold labeled with anti-MpPIntO1 (A and B at 1:100 dilution), with the corresponding preimmune serum (C, 1:50) or with anti-MpC002 (D, 1:100), or the corresponding preimmune serum (E, 1:50). Examples of gold-labeling, when present, are indicated with arrows. Compartments are indicated as: ST, stylet track; IS, intercellular space; Cy, cytoplasm; V, vacuole; CW, cell wall; Ve, vesicles; P, plastid; and M, mitochondria. Scale bars all indicate $500 \mathrm{~nm}$. 
labeling of any cell type in the vascular tissue in experimental compared with the control samples, suggesting that Mp10 is not delivered into the vasculature or is not present at high enough concentrations for detection in these tissues.

We also investigated labeling with antisera to MpOS-D1, a family member of Mp10, in and near stylet tracks. We did not detect specific labeling of mesophyll or vascular tissues with MpOS-D1 antisera in or near GPA feeding sites, as compared with controls. While the Mp-OSD1 antisera detected denatured MpOS-D1 protein on immuno-blots (Fig. 1), it is possible that these antisera do not detect this effector in resin sections. Alternatively, GPA may not deliver Mp-OSD1 or delivers this effector at low concentrations or to different locations inside plant tissues compared with Mp10.

\section{Aphid effector MpPIntO1 localizes to the sheaths surrounding aphid stylets at feeding sites.}

To compare localizations of aphid effectors, we also conducted IGL with antisera to MpPIntO1 and MpC002 on ultrathin sections of tissues containing aphid stylet tracks. We observed very strong and specific labeling of the stylet sheaths by the MpPIntO1 antisera (Fig. 4B) but not by the corresponding preimmune serum (Fig. 4C).The MpC002 antisera also labeled the sheaths more strongly than other tissues in the plant and this labeling was stronger than detected with the corresponding preimmune sera (Fig. 4D to E). However, the background labeling of uninfested plant tissue by the MpC002 antisera was much higher than for MpPIntO1, suggesting that anti-MpC002 may be less specific. These data suggest that MpPIntO1, and possibly $\mathrm{MpC002}$ also, are found in the sheaths that surround the stylets during feeding.

\section{DISCUSSION}

In this study, we generated specific antisera to the GPA proteins Mp10, MpOS-D1, MpC002, and MpPIntO1, which were previously shown to have activities characteristic of effector proteins (Bos et al. 2010; Mutti et al. 2008; Pitino and Hogenhout 2013; Pitino et al. 2011), and used these antisera in IGL experiments to examine if GPA secretes effector proteins into plants during feeding. We found that the Mp10 antisera specifically labeled the cytoplasm and chloroplasts of mesophyll cells adjacent to the aphid stylet tracks. No such labeling was observed in cells further distal to the stylet tracks. In addition, IGL experiments with the antisera to the three other effectors did not label these compartments. Finally, we observed no or much reduced labeling densities in the preimmune sera and uninfested controls. Taken together, these experiments provide strong evidence for Mp10 delivery by secretion in the watery saliva by GPA into mesophyll cells, while Mp10 resides in the cytosol and the chloroplasts.

Mp10 and MpOS-D1 are members of the chemosensory protein family that were first identified in the haemolymph of sensory organs. However, it is emerging that members of this family are expressed across many nonsensory tissues and may have diverse roles in processes other than chemoreception, including pheromone delivery and development (Guo et al. 2011; Kitabayashi et al. 1998; Maleszka et al. 2007), and in the case of Mp10 modulation of host plant immunity (Bos et al. 2010; Rodriguez et al. 2014). CSPs have cental hydrophobic channels that are thought to bind small ligands (Lartigue et al. 2002; Mosbah et al. 2003). Interestingly, the saliva of mosquitoes and other blood-feeding dipterans contain D7 proteins that are structurally related to members of the arthropod odorant binding protein superfamily and, like CSPs, are small chemosensory proteins with globular structures and ligand-binding central hydrophobic channels (Calvo et al. 2006, 2009). The D7 protein family members are anti-inflammatory mediators by binding host amines and leukotrienes resulting in, for example, inhibition of collagenmediated platelet activation (Alvarenga et al. 2010). Thus, Mp10 may modulate plant defense responses by binding small immunosuppressive plant metabolites.

We previously found that Mp10 suppresses the flg22-induced ROS burst (Bos et al. 2010) that is dependent on BAK1 (Chinchilla et al. 2007). The ROS burst seen in response to aphid elicitors is also dependent on BAK1 (Chaudhary et al. 2014; Prince et al. 2014). BAK1 is a key regulator of several plasma membrane-localized PRRs, which sense potential invaders early on and trigger downstream immune signaling. Thus, given that we found Mp10 in the cytoplasm of mesophyll cells adjacent to stylet tracks, this effector may suppress the ROS burst induced by aphids shortly after initial probing by the aphid in the pathway phase. The additional detection of Mp10 in chloroplasts is of interest because chloroplasts are a major source of ROS and have a critical role in PTI (Caplan et al. 2015; Nomura et al. 2012; Shapiguzov et al. 2012). Given that Mp10 does not appear to have an obvious plastid transit peptide sequence, it is unclear how this protein gets into chloroplasts. As a small protein, Mp10 may migrate into chloroplast passively or via interaction with ligands that are located predominantly in these cell organelles.

In addition to the suppression of PTI, heterologous expression of Mp10 in plants elicits an effector-triggered immunitytype response, leading to chlorosis and activation of jasmonic acid and salicylic acid signaling pathways (Bos et al. 2010; Rodriguez et al. 2014). However, in these expression experiments Mp10 is present at high levels in many cells, whereas our data indicate that Mp10 is delivered in only some cells near the aphid stylets in the presence of other effectors (such as MpPIntO1). Hence, it remains to be investigated how Mp10 modulates cell defense responses during aphid feeding.

Our IGL data show different localizations of MpPIntO1 and MpC002 compared with Mp10. MpPIntO1 and MpC002 are abundant proteins in aphid saliva and can be readily detected by protein immuno-blotting in artificial diets fed upon by aphids and extracts of aphid-exposed leaves (Harmel et al. 2008; Mutti et al. 2008). Our IGL data provide evidence that MpPIntO1 and, possibly, also MpC002 are present in the stylet sheaths. We did not detect MpPIntO1 inside plant mesophyll and vascular cells, indicating that aphids do not deliver this effector inside these cells or else they are present at or below detection-level concentrations. Our data are in agreement with previous findings, showing that MpPIntO1 is abundant in the gelling saliva that generates the sheaths (Harmel et al. 2008), though MpPIntO1 and $\mathrm{MpCOO2}$ are also found in soluble saliva in artificial diets fed upon by aphids (Chaudhary et al. 2015; Harmel et al. 2008; Will et al. 2012). However, given that both MpPIntO1 and $\mathrm{MpC} 002$ are abundant, it is possible that some of these proteins are not captured during the gelling process and end up in the soluble saliva fraction. We previously found that aphids reproduce better on transgenic $A$. thaliana that produce MpPIntO1 and $\mathrm{MpC} 002$ under control of $35 \mathrm{~S}$ promoters (Pitino and Hogenhout 2013), though the effect of MpPIntO1 on aphid performance is variable (Elzinga et al. 2014; Pitino and Hogenhout 2013). In addition, RNA interference (RNAi)-mediated knock down of $\mathrm{MpC002}$ in aphids reduced aphid performance on plants, whereas MpPIntO1-RNAi aphids were not affected (Pitino et al. 2011). Several pathogens deliver effectors in the apoplastic space to modulate defense responses (De Wit 2016; Tian et al. 2004, 2007). Our IGL data open up the possibility that the aphid MpPIntO1 and MpC002 effectors act in the plant apoplast from within sheath saliva.

In some cases, changes in subcellular structures occur in response to aphid feeding (Fig. 3A and $\mathrm{C}$ ). It is known that 
pathogen attack can induce dramatic reorganizations of subcellular structures, including organelles (Ben Khaled et al. 2015; Hardham et al. 2008). Aphids can also cause significant tissue damage and disruption of plant tissue during feeding (Saheed et al. 2007). Moreover, probing of cells by aphid stylets induces a rapid subcellular relocalization of vesicle-associated Cauliflower mosaic virus particles that is essential for the acquisition and transmission of this virus by aphids (Martiniere et al. 2013). The increase in abundance of vesicular structures we observed might be associated with the activation of plant defense responses, such as the delivery of defense compounds via vesicles to deter attack. Alternatively, aphid effectors may modulate plant cell processes, such as the reprogramming of vesicle trafficking, as has been shown to occur for pathogens (Ben Khaled et al. 2015; Bozkurt et al. 2015).

\section{MATERIALS AND METHODS}

\section{Antibody generation.}

Coding sequences corresponding to the predicted mature effector proteins (minus predicted secretory signal peptide) were expressed in Escherichia coli as $N$-terminal 6XHis tag fusions (Mp10, MpPIntO1, and MpOSD1) or as an $N$-terminal carcinoembryonic-antigen and 6XHis tag fusion (MpC002), were purified, and were checked for purity by protein immunoblotting using anti-His-tag antibody (BacPower and FoldArt technologies, Genscript). Proteins were injected into chicken (Mp10) or rabbit (MpOSD1, MpPIntO1, and MpC002) by Genscript. Specific antisera were affinity-purified using immobilized recombinant protein. Aliquots of preimmune serum were collected from the animals before injection.

\section{Western blotting.}

Arabidopsis thaliana Col-0 plants were exposed to GPA (Myzus persicae clone $\mathrm{O}$ ) for $24 \mathrm{~h}$ (1,000 aphids per threeweek-old plant), aphids were carefully removed, and the plant rosette was rinsed in distilled water to remove any remaining aphid material from the surface. Total protein was extracted from plant and aphids in sodium dodecyl sulfate (SDS) buffer $(5 \mu \mathrm{l}$ per milligram of plant tissue or $200 \mu \mathrm{l}$ per milligram of aphid tissue), and $10 \mu \mathrm{l}$ was size-separated by SDSpolyacrylamide gel electrophoresis and was blotted onto nitrocellulose membrane, using standard methods. Blots were probed overnight with 1:100 or 1:1,000 antibody dilutions (or with preimmune sera at double the concentrations) and a secondary antibody-horseradish peroxidase conjugate.

\section{Immuno-localization.}

Samples were harvested from aphid-infested (or uninfested) A. thaliana plants and were immediately fixed in $4 \%$ formaldehyde and $0.5 \%$ glutaraldehyde in phosphate-buffered saline (PBS) at $4^{\circ} \mathrm{C}$ overnight. The samples were then embedded in LR White resin (Agar Scientific), using the progressive lowering of temperature method, with the Leica EM AFS2 (automatic freeze substitution) machine (Caillaud et al. 2014). Sections were prepared on a Leica UC6 ultramicrotome. Sections of $0.5 \mu \mathrm{m}$ were stained with toluidine blue for light microscopy (Nikon Microphot-SA) and ultrathin sections of approximately $90 \mathrm{~nm}$ were picked up onto pyroxylin- and carbon-coated gold grids (Agar Scientific) for immuno-labeling.

The ultrathin sections were immuno-gold labeled according to the following protocol: $50 \mathrm{mM}$ glycine on PBS for $15 \mathrm{~min}$; Aurion blocking buffer (Aurion) for $30 \mathrm{~min}$; 0.1\% acetylated bovine serum albumin $\mathrm{C}$ (Aurion) in PBS (BSA-C/PBS) two times for $5 \mathrm{~min}$; primary antibody of choice at $1: 10$ to $1: 100$ dilutions in $0.1 \%$ BSA-C/PBS for $90 \mathrm{~min}$; $0.1 \%$ BSA-C/PBS six times for $5 \mathrm{~min}$; secondary antibody conjugated to $10 \mathrm{~nm}$ gold particles $(1 / 40$ dilution in $0.1 \%$ BSA-C/PBS) for $90 \mathrm{~min}$; $0.1 \%$ BSA-C/PBS six times for $5 \mathrm{~min}$; PBS two times for $5 \mathrm{~min}$; and water two times for $3 \mathrm{~min}$.

Grids were viewed in a FEI Tecnai 20 transmission electron microscope (FEI UK Ltd.) at $200 \mathrm{kV}$ and were imaged using an AMT XR60 digital camera (Deben) to record TIF files. Images were analyzed using ImageJ. The areas and the numbers of gold particles detected in each subcellular compartment were measured across a series of images across each sample. The density across different compartments in infested or uninfested samples were analyzed by general linear model (Genstat). Where differences in labeling intensity were detected between aphidinfested and uninfested samples, replicate sections were probed with the corresponding preimmune serum, at a higher concentration than the antibody was used at, to demonstrate that labeling was specific.

\section{ACKNOWLEDGMENTS}

We thank the members of the Hogenhout lab for useful discussions and feedback and the Biotechnology and Biological Sciences Research Council for funding $(\mathrm{BB} / \mathrm{J} 0045531 / 1)$.

\section{LITERATURE CITED}

Alvarenga, P. H., Francischetti, I. M., Calvo, E., Sá-Nunes, A., Ribeiro, J. M., and Andersen, J. F. 2010. The function and three-dimensional structure of a thromboxane A2/cysteinyl leukotriene-binding protein from the saliva of a mosquito vector of the malaria parasite. PLoS Biol 8:e1000547.

Atamian, H. S., Chaudhary, R., Cin, V. D., Bao, E., Girke, T., and Kaloshian, I. 2013. In planta expression or delivery of potato aphid Macrosiphum euphorbiae effectors Me10 and Me23 enhances aphid fecundity. Mol. Plant-Microbe Interact. 26:67-74.

Ben Khaled, S. B., Postma, J., and Robatzek, S. 2015. A moving view: Subcellular trafficking processes in pattern recognition receptortriggered plant immunity. Annu. Rev. Phytopathol. 53:379-402.

Bos, J. I. B., Prince, D., Pitino, M., Maffei, M. E., Win, J., and Hogenhout, S. A. 2010. A functional genomics approach identifies candidate effectors from the aphid species Myzus persicae (green peach aphid). PLoS Genet. 6:e1001216.

Bozkurt, T. O., Belhaj, K., Dagdas, Y. F., Chaparro-Garcia, A., Wu, C. H., Cano, L. M., and Kamoun, S. 2015. Rerouting of plant late endocytic trafficking toward a pathogen interface. Traffic 16:204-26.

Caillaud, M.-C., Wirthmueller, L., Sklenar, J., Findlay, K., Piquerez, S. J. M., Jones, A. M., Robatzek, S., Jones, J. D., and Faulkner, C. 2014 The plasmodesmal protein PDLP1 localises to haustoria-associated membranes during downy mildew infection and regulates callose deposition. PLoS Pathog. 10:e1004496.

Calvo, E., Mans, B. J., Andersen, J. M., and Robeiro, J. M. C. 2006. Function and evolution of a mosquito salivary protein family. J. Biol. Chem. 281:1935-42.

Calvo, E., Mans, B. J., Ribeiro, J. M., and Andersen, J. F. 2009. Multifunctionality and mechanism of ligand binding in a mosquito antiinflammatory protein. Proc. Natl. Acad. Sci. U.S.A. 106:37283733

Caplan, J. L., Kumar, A. S., Park, E., Padmanabhan, M. S., Hoban, K., Modla, S., Czymmek, K., and Dinesh-Kumar, S. P. 2015. Chloroplast stromules function during innate immunity. Dev. Cell 34:45-57.

Carolan, J. C., Fitzroy, C. I. J., Ashton, P. D., Douglas, A. E., and Wilkinson, T. L. 2009. The secreted salivary proteome of the pea aphid Acyrthosiphon pisum characterised by mass spectrometry. Proteomics 9:2457-2467

Chaudhary, R., Atamian, H. S., Shen, Z., Briggs, S. P., and Kaloshian, I. 2014. GroEL from the endosymbiont Buchnera aphidicola betrays the aphid by triggering plant defence. Proc. Natl. Acad. Sci. U.S.A. 111: 8919-8924.

Chaudhary, R., Atamian, H. S., Shen, Z., Briggs, S. P., and Kaloshian, I. 2015. Potato aphid salivary proteome: Enhanced salivation using resorcinol and identification of aphid phosphoproteins. J. Proteome Res. 14:1762-1778.

Chinchilla, D., Zipfel, C., Robatzek, S., Kemmerling, B., Nürnberger, T., Jones, J. D. G., Felix, G., and Boller, T. 2007. A flagellin-induced complex of the receptor FLS2 and BAK1 initiates plant defence. Nature 448:497-500 
Coleman, A. D., Wouters, R. H., Mugford, S. T., and Hogenhout, S. A. 2015. Persistence and transgenerational effect of plant-mediated RNAi in aphids. J. Exp. Bot. 66:541-8.

Cooper, W. R., Dillwith, J. W., and Puterka, G. J. 2010. Salivary proteins of Russian wheat aphid (Hemiptera: Aphididae). Environ. Entomol. 39: 223-231.

De Wit, P. J. 2016. Apoplastic fungal effectors in historic perspective: A personal view. New Phytol. doi:10.1111/nph.14144.

Dodds, P. N., and Rathjen, J. P. 2010. Plant immunity: Towards an integrated view of plant-pathogen interactions. Nat. Rev. Genet. 11:539548.

Elzinga, D., De Vos, M., and Jander, G. 2014. Suppression of plant defenses by a Myzus persicae (green peach aphid) salivary effector protein. Mol. Plant-Microbe Interact. 27:747-756.

Gopalan, S., Bauer, D. W., Alfano, J. R., Loniello, O., He, S. Y., and Collmer, A. 1998. Expression of the Pseudomonas syringae avirulence protein AvrB in plant cells alleviates its dependence on the hypersensitive response and pathogenicity (Hrp) secretion system in eliciting genotype-specific hypersensitive cell death. Plant Cell 8:1095-1105.

Guerrieri, E., and Digilio, M. C. 2008. Aphid-plant interactions: A review. J. Plant Interact. 3:223-232.

Guo, R., Wang, X., Ma, Z., Xue, L., Han, J., Yu, D., and Kang, L. 2011. CSP and takeout genes modulate the switch between attraction and repulsion during behavioral phase change in the migratory locust. PLoS Genet. 7: e1001291.

Guo, K., Wang, W., Luo, L., Chen, J., Guo, Y., and Cui, F. 2014. Characterization of an aphid-specific, cysteine-rich protein enriched in salivary glands. Biophys. Chem. 189:25-32.

Hardham, A. R., Takemoto, D., and White, R. G. 2008. Rapid and dynamic subcellular reorganization following mechanical stimulation of Arabidopsis epidermal cells mimics responses to fungal and oomycete attack. BMC Plant Biol. 8:63.

Harmel, N., Létocart, E., Cherqui, A., Giordanengo, P., Mazzucchelli, G., Guillonneau, F., De Pauw, E., Haubruge, E., and Francis, F. 2008. Identification of aphid salivary proteins: A proteomic investigation of Myzus persicae. Insect Mol. Biol. 17:165-174.

Hogenhout, S. A., Ammar, E.-D., Whitfield, A. E., and Redinbaugh, M. G. 2008. Insect vector interactions with persistently transmitted viruses. Annu. Rev. Phytopathol. 46:327-359.

Kitabayashi, A. N., Arai, T., Kubo, T., and Natori, S. 1998. Molecular cloning of cDNA for p10, a novel protein that increases in the regenerating legs of Periplanet aamericana (American cockroach). Insect Biochem. Mol. Biol. 28:785-790.

Lartigue, A., Campanacci, V., Roussel, A., Larsson, A. M., Jones, T. A., Tegoni, M., and Cambillau, C. 2002. X-ray structure and ligand binding study of a moth chemosensory protein. J. Biol. Chem. 277:32094-32098.

Maleszka, J., Foret, S., Saint, R., and Maleszka, R. 2007. RNAi-induced phenotypes suggest a novel role for a chemosensory protein CSP5 in the development of embryonic integument in the honeybee (Apis mellifera). Dev. Genes Evol. 217:189-196.

Martín, B., Collar, J. L., Tjallingii, W. F., and Fereres, A. 1997. Intracellular ingestion and salivation by aphids may cause the acquisition and inoculation of non-persistently transmitted plant viruses. J. Gen. Virol. 78:2701-2705.

Martiniere, A., Bak, A., Macia, J. L., Lautredou, N., Gargani, D., Doumayrou, J., Garzo, E., Moreno, A., Fereres, A., Blanc, S., and Drucker, M. 2013. A virus responds instantly to the presence of the vector on the host and forms transmission morphs. eLife 2013:1-26.

Miles, P. W. 1999. Aphid saliva. Biol. Rev. 74:41-85.

Mosbah, A., Campanacci, V., Lartigue, A., Tegoni, M., Cambillau, C., and Darbon, H. 2003. Solution structure of a chemosensory protein from the moth Mamestra brassicae. Biochem. J. 369:39-44.

Musser, R. O., Hum-Musser, S. M., Eichenseer, H., Peiffer, M., Ervin, G., Murphy, J. B., and Felton, G. W. 2002. Herbivory: Caterpillar saliva beats plant defences. Nature 416:599-600.

Mutti, N. S., Louis, J., Pappan, L. K., Pappan, K., Begum, K., Chen, M. S., Park, Y., Dittmer, N., Marshall, J., Reese, J. C., and Reeck, G. R. 2008. A protein from the salivary glands of the pea aphid, Acyrthosiphon pisum, is essential in feeding on a host plant. Proc. Natl. Acad. Sci. U.S.A. 105:9965-9969.

Naessens, E., Dubreuil, G., Giordanengo, P., Baron, O. L., Minet-Kebdani, N., Keller, H., and Coustau, C. 2015. A secreted MIF cytokine enables aphid feeding and represses plant immune responses. Curr. Biol. 25: 1898-1903.

Nicholson, S. J., and Puterka, G. J. 2014. Variation in the salivary proteomes of differentially virulent greenbug (Schizaphis graminum Rondani) biotypes. J. Proteomics 105:186-203.
Nicholson, S. J., Hartson, S. D., and Puterka, G. J. 2012. Proteomic analysis of secreted saliva from Russian wheat aphid (Diuraphis noxia Kurd.) biotypes that differ in virulence to wheat. J. Proteomics 75 2252-2268.

Nomura, H., Komori, T., Uemura, S., Kanda, Y., Shimotani, K., Nakai, K., Furuichi, T., Takebayashi, K., Sugimoto, T., Sano, S., Suwastika, I. N., Fukusaki, E., Yoshioka, H., Nakahira, Y., and Shiina, T. 2012 Chloroplast-mediated activation of plant immune signalling in Arabidopsis. Nat. Commun. 3:926.

Orlovskis, Z., Canale, M. C., Thole, V., Pecher, P., Lopes, J. R. S., and Hogenhout, S. A. 2015. Insect-borne plant pathogenic bacteria: Getting a ride goes beyond physical contact. Curr. Opin. Insect Sci. 9:16-23.

Petre, B., and Kamoun, S. 2014. How do filamentous pathogens deliver effector proteins into plant cells? PLoS Biol. 12:e1001801.

Pitino, M., and Hogenhout, S. A. 2013. Aphid protein effectors promote aphid colonization in a plant species-specific manner. Mol. PlantMicrobe Interact. 26:130-139.

Pitino, M., Coleman, A. D., Maffei, M. E., Ridout, C. J., and Hogenhout, S. A. 2011. Silencing of aphid genes by dsRNA feeding from plants PLoS One 6:e25709.

Prince, D. C., Drurey, C., Zipfel, C., and Hogenhout, S. A. 2014. The leucinerich repeat receptor-like kinase BRASSINOSTEROID INSENSITIVE1ASSOCIATED KINASE1 and the cytochrome P450 PHYTOALEXIN DEFICIENT3 contribute to innate immunity to aphids in Arabidopsis. Plant Physiol. 164:2207-2219.

Ramsey, J. S., Wilson, A. C., de Vos, M., Sun, Q., Tamborindeguy, C., Winfield, A., Malloch, G., Smith, D. M., Fenton, B., Gray, S. M., and Jander, G. 2007. Genomic resources for Myzus persicae: EST sequencing, SNP identification, and microarray design. BMC Genomics $8: 423$.

Rao, S. A. K., Carolan, J. C., and Wilkinson, T. L. 2013. Proteomic profiling of cereal aphid saliva reveals both ubiquitous and adaptive secreted proteins. PLoS One 8:e57413.

Rodriguez, P., Stam, R., Warbroek, T., and Bos, J. I. B. 2014. Mp10 and Mp42 from the aphid species Myzus persicae trigger plant defenses in Nicotiana benthamiana through different activities. Mol. Plant-Microbe Interact. 27:30-39.

Saheed, S. A., Liu, L., Jonsson, L., and Botha, C. E. J. 2007. Xylem-as well as phloem-sustains severe damage due to feeding by the Russian wheat aphid. S. Afr. J. Bot. 73:593-599.

Shapiguzov, A., Vainonen, J. P., Wrzaczek, M., and Kangasjärvi, J. 2012. ROS-talk-How the apoplast, the chloroplast, and the nucleus get the message through. Front. Plant Sci. 3:292.

Stuart, J. J., Chen, M. S., Shukle, R., and Harris, M. O. 2012. Gall midges (hessian flies) as plant pathogens. Annu. Rev. Phytopathol. 50:339-357.

Tian, M., Huitema, E., da Cunha, L., Torto-Alalibo, T., and Kamoun, S. 2004. A kazal-like extracellular serine protease inhibitor from Phytophthora infestans targets the tomato pathogenesis-related protease P69B*. J. Biol. Chem. 279:26370-26377.

Tian, M., Win, J., Song, J., van der Hoorn, R., van der Knaap, E., and Kamoun, S. 2007. A Phytophthora infestans cystatin-like protein targets a novel tomato papain-like apoplastic protease. Plant Physiol. 143: 364-377.

Tjallingii, W. F. 2006. Salivary secretions by aphids interacting with proteins of phloem wound responses. J. Exp. Bot. 57:739-745.

Tjallingii, W. F., and Esch, T. H. 1993. Fine structure of aphid stylet routes in plant tissues in correlation with EPG signals. Physiol. Entomol. 18: 317-328.

Vandermoten, S., Harmel, N., Mazzucchelli, G, De Pauw, E., Haubruge, E., and Francis, F. 2014. Comparative analyses of salivary proteins from three aphid species. Insect Mol. Biol. 23:67-77.

Wang, W., Dai, H., Zhang, Y., Chandrasekar, R., Luo, L., Hiromasa, Y., Sheng, C., Peng, G., Chen, S., Tomich, J. M., Reese, J., Edwards, O., Kang, L., Reeck, G., and Cui, F. 2015. Armet is an effector protein mediating aphid-plant interactions. FASEB J. 29:2032-2045.

Will, T., Steckbauer, K., Hardt, M., and van Bel, A. J. E. 2012. Aphid gel saliva: Sheath structure, protein composition and secretory dependence on stylet-tip milieu. PLoS ONE 7:e46903.

Will, T., Tjallingii, W. F., Thönnessen, A., and van Bel, A. J. E. 2007 Molecular sabotage of plant defence by aphid saliva. Proc. Natl. Acad. Sci. U.S.A. 104:10536-10541.

Zhou, J. J., Vieira, F. G., He, X. L., Smadja, C., Liu, R., Rozas, J., and Field, L. M. 2010. Genome annotation and comparative analyses of the odorant-binding proteins and chemosensory proteins in the pea aphid Acyrthosiphon pisum. Insect Mol. Biol. 19:113-122. 